\title{
UNA PINTURA MÁS DE BALTASAR DE ECHAVE IBİA
}

\author{
Elisa Vargas Lugo
}

La figura y la obra del pintor Baltasar de Echave Ibía, quien fuera uno de los más destacados pinceles del siglo XVII, está aún por estudiarse en gran medida. Por lo tanto, el presente artículo solamente pretende dar a conocer una obra que hasta ahora no había sido registrada por ninguno de los especialistas, aceptando de antemano que las suposiciones que aquí se hacen sobre dicha pintura, podrían ser modificadas cuando se conozca mejor la trayectoria del artista. Como es del conocimiento de los especialistas, no se sabe la fecha en que nació este pintor. Existe el acta de su casamiento, efectuado en $1623 .{ }^{1}$ En vista de lo cual, la suposición que comparten Manuel Toussaint ${ }^{2}$ y Diego Angulo Iñiguez, en el sentido de que Baltasar de Echave Ibía debió haber nacido hacia 1580-84 no parece acertada, puesto que, de haber sido así, el pintor tendría por lo menos cuarenta años al contraer matrimonio, lo que no es congruente con las costumbres de esa época, aunque, desde luego, no es imposible que así hubiera sucedido. La suposición, en cambio, de que murió hacia mediados del $\mathrm{XVII}^{3}$ parece aceptable, dada la corta producción que se conoce de él. Por el momento, rectificar, enriquecer o precisar esta información cronológica no está al alcance de mis conocimientos.

Muy importantes para esta presentación son las opiniones tanto del maestro Toussaint como del maestro Angulo Íniguez sobre la calidad expresiva de la pintura de este artista.

Según Manuel Toussaint,

.. .su desatrollo parece tan íntimamente ligado al del padre, que en muchos casos sentimos la colaboración íntima de ambos artistas. Pero que en Echave lbía latían inquietudes personales que modestamente protestaban contra la avasallante figura del maestro, nos lo muestra el estudio de sus cuadros. Esa afición por las coloraciones azules en los fondos, que me ha permitido Ilamarle el Echave de los Azules. Existe, en efecto, en sus cuadros el gusto por paisajes de entonaciones azulosas llevadas

${ }^{1}$ Archivo Sagrario Metropolitano. Libro 4 de Matrimonios, fol $30 \mathrm{v}$ Apud Francisco Pérez de Salazar, Historia de la pintura en Puebla, México, UNAM, 1963, p. 179

${ }^{2}$ Manuel Toussaint, Arte Colonial en México, México, UNAM, 1983, 4a. edición, p. 73, y Diego Angulo fñiguez, Historia del Arte Hispanoamericano, Barcelona, Salvat, 1950. 3 vols., tomo II, p. 399.

I Ibidem, tomo II, p. 399. 
a una variedad extraordinaria de matices. No hay duda de que se trata de una coloración convencional, pero que siguió después de la contemplación de la naturaleza, porque no es posible pensar que él haya inventado esa tonalidad que aparece tan frecuentemente en los crepúsculos de México. ${ }^{4}$

Por su parte, el maestro Angulo Îniguez dejó escrito que la obra de este pintor muestra dos facetas, ". . .la del pintor de composiciones. .." y ". . .la del paisajista". ". Acerca de esta habilidad de Echave Ibía, Angulo Íñiguez recuerda los lienzos flamencos ". . que por aquellos años inundaban el mercado español y en los cuales se condede al paisaje el interés que es característico de la escuela..." Afirma que el ejercicio de la pintura de paisaje le creó - a este Echave- una sensibilidad particular por los azules, por lo que le parece muy atinado, por parte de Toussaint ${ }^{6}$ haber diferenciado a este artista - de los demás del mismo apellido- como "el Echave de los azules".

Fue don Diego Angulo quien primero hizo notar que si bien Echave Ibía había seguido en algunas de sus obras el ejemplo de los manieristas tardíos sevillanos -aspecto que por cierto es necesario profundizar para que pueda ser corroborado de manera más clara- se sintió también "llamado hacia el naturalismo"?

A más de treinta años de distancia de cuando los ilustres autores que han sido citados emitieron tales opiniones, puede decirse, en suma, que efectivamente en la pintura de Echave Ibía se reconocen, desde luego, las enseñanzas de su padre en el dibujo firme, fino, bien definido; en el tratamiento de los paños, de las manos y de los pies; en el tipo de angelitos que representó y en la manera armoniosa de hacer composiciones. El predominio de los azules resulta un hecho irrefutable - que se confirma una vez más con la obra que se presenta- y cuýo origen debe verse, tal como lo vio Angulo Íniguez, en la pintura flamenca, y aceptamos con este autor que para el logro de tales entonaciones debe de haber contado también el gusto de Echave Ibía por reproducir paisajes. Su inclinación por la expresión naturalista parece ser predominante sobre las influencias manieristas; pero aún hace falta conocer más la obra de este pintor, para poder sostener esta última afirmación de manera categórica.

Sañ Jerónimo -el austero penitente, doctor de la Iglesia y erudito traductor del Antiguo Testamento- en sus años de retiro en el desierto es el asunto que se representa en un lienzo que se localiza en la catedral de la

${ }^{4}$ Manuel Toussaint, op cit, p. 73.

${ }^{\circ}$ Diego Angulo fñiguez, op cit, pp. 399-401

6 Ibidem

i Ibidem 
ciudad de Zamora, Mich. Mide dicha pintura $1.90 \times 1.22 \mathrm{~m}$ y se encuentra dentro de su original marco tallado y dorado.

Los biógrafos del santo relatan que éste se retiró voluntariamente, por un lapso de cuatro años, en el desierto de Siria, para estudiar, meditar y hacer penitencia. Vivió san Jerónimo dentro de una cueva, acompañado por un león, fiera que se llenó de mansedumbre y se apegó al santo debido a que, en una ocasión, san Jerónimo le sacó una espina que el felino llevaba enterrada en una pata. Hubo de luchar el santo con múltiples tentaciones y quizá por eso fue muy temeroso del Juicio Final, por lo que algunas veces - dicen sus biógrafos - imaginaba escuchar la trompeta que, según las Sagradas Escrituras, sería tocada por un ángel cuando ese Día llegara. Tal como se dijo, este pasaje de la vida de san Jerónimo es el que representó Echave Ibía, al pie de la letra, como puede comprobarse en las fotografías adjuntas.

La obra sorprende por su buena calidad en la que resaltan las características distintivas del artista: el artificioso paisaje azul destaca de inmediato, con sus formas "de receta" y haciendo fuerte contraste claroscurista y barroco con el oscuro ámbito de la cueva donde se encuentra sentado el santo. La actitud corporal del anciano, sus ademanes, su mirada, retienen el instante preciso en el que el alertador sonido de la trompeta del ángel llegó a sus oídos, sobrecogiéndolo. Su actitud y expresión parecen un llamado de atención al espectador.

El desnudo del anciano ostenta un vigor realista, poco frecuente en la pintura novohispana. La túnica roja -intencionalmente caída por debajo de la cintura para dejar descubiertos el torso y una pierna - tiene ciertamente la magnífica calidad de paños que pueden encontrarse en las pinturas de Echave Orio, aunque con menos brillos zigzagueantes en los dobleces. El angelito que toca la corneta es una figura que a todas luces pertenece a la familia angélica que desciende tanto de Martín de Vos como de Echave Ibía y Luis Juárez. El parentesco plástico se ve en la piel de intensa blancura rosada, en la frente desmesurada y los cabellos tan rubios que son casi blancos, volátiles y escasos. Así pues, en la composición se combinan tres directrices: las recetas flamencas del azuloso paisaje matizado con ocres, con un suave manierismo en el discreto acomodo geometricista de los paños y con un predominante realismo representado con el más fino oficio posible. Las alitas del ángel, aunque implantadas demasiado cerca de los hombros, ostentan un plumaje naturalista. El cuerpo y sobre todo el rostro del anciano se apegan con fidelidad a la figura humana en todos sus detalles, al grado de que se tiene la impresión de estar frente a un modelo real. Los dedos magros, tanto del pie como de las delgadas manos; 
los pliegues de la cintura, el ombligo, el rostro con su barba, sus arrugas, las depresiones en las mejillas, todo el tratamiento de estas partes muestra con cuánto empeño el pintor se "inclinaba al naturalismo".

Por lo que se refiere al rostro, éste se parece enormemente al del "San Juan" firmado por Echave Ibía, si bien el evangelista ostenta, como era debido, un rostro joven. Sin embargo, como puede verse al comparar las ilustraciones adjuntas, ambos lucen la misma nariz larga y recta, los mismos ojos grandes, negros, bien abiertos. El labio inferior, grande y grueso, también hermana los dos rostros. Pero donde el realismo alcanza su mayor esplendor, sus mayores y más finas calidades, es en la representación de los objetos que se ven sobre la mesa enfrente de san Jerónimo. La estera, el cráneo humano, el cuaderno de notas, los tinteros, el cuchillo, las tijeras, los libros, los silicios, en fin, todos y cada uno de los objetos están perfectamente dibujados y pintados, de acuerdo con el más minucioso y perfecto realismo. En cambio, la cabeza del león que aparece debajo del banco donde se sienta el santo no es en realidad la cabeza de un león, sino la de un felino de extraña especie; representación convencional, inventada por el pintor, como casi toda la pintura animalística que se hizo en el arte novohispano por falta de conocimiento y de observación de la naturaleza.

El conjunto es espléndido y por fortuna está en condiciones bastante buenas, aunque sí sería necesario darle un tratamiento de conservación y arreglar dos o tres pequeñas roturas que felizmente no afectan ninguna parte importante de la composición.

La firma se localiza por encima de la cabeza del león. Su trazo, como consta en la fotografía anexa, es igual al que presentan las firmas ya regis. tradas de este pintor. ${ }^{8}$

Por su tamaño y calidad artística no cabe duda que esta pintura entra al repertorio de Baltasar de Echave Ibía como uno de sus mejores lienzos, que posiblemente pudiera fecharse hacia 1628, que es la fecha en que firmó el Bautismo de Cristo que se conserva en el convento de Xochimilco y que ostenta calidad semejante. También debe considerarse esta pintura como uno de los mejores ejemplos de arte realista del siglo XVII a pesar de que esta directriz artística, por razones filosóficas de la época, no mereció estímulo especial, ${ }^{9}$ por ser, êi cierto modo, contraria a la afanosa búsqueda de los valores espirituales e intangibles.

\$Cfr. Abelardo Carrillo y Gariel, Autógratos de pintores coloniales, México, UNAM, 1972, p 51 .

"Cfr. Elisa Vatgas Lugo, "La expresión pictórica teligiosa y la sociedad colonial", Anales del Instituto de Investigaciones Estéticas, México, UNAM, 1982, No. 50-1, pp. 61.76 
DOI: http://dx.doi.org/10.22201/iie.18703062e.1987.58.1351

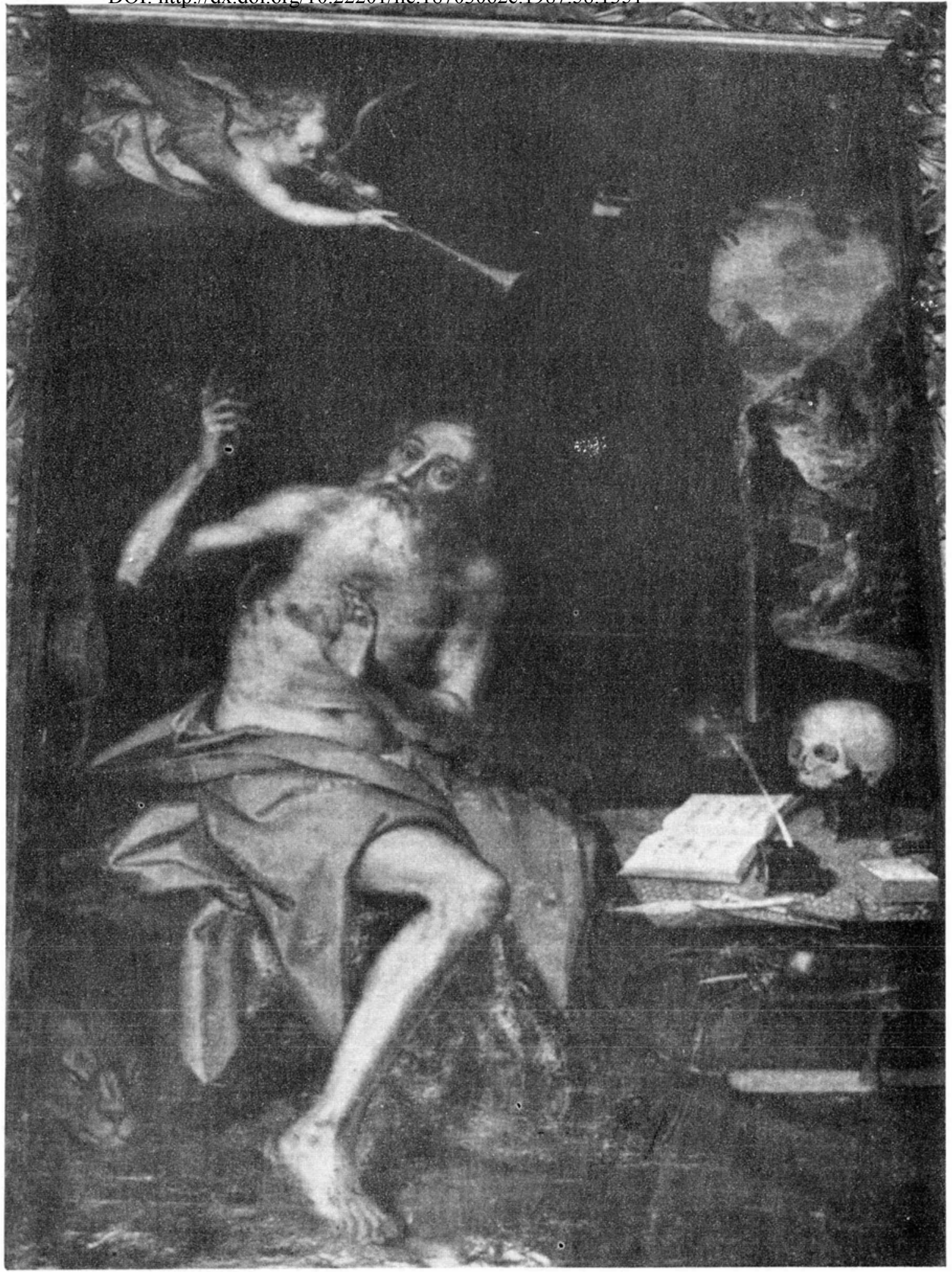

Figura 1. San Jerónimo. Baltasar de Echave Ibía. 


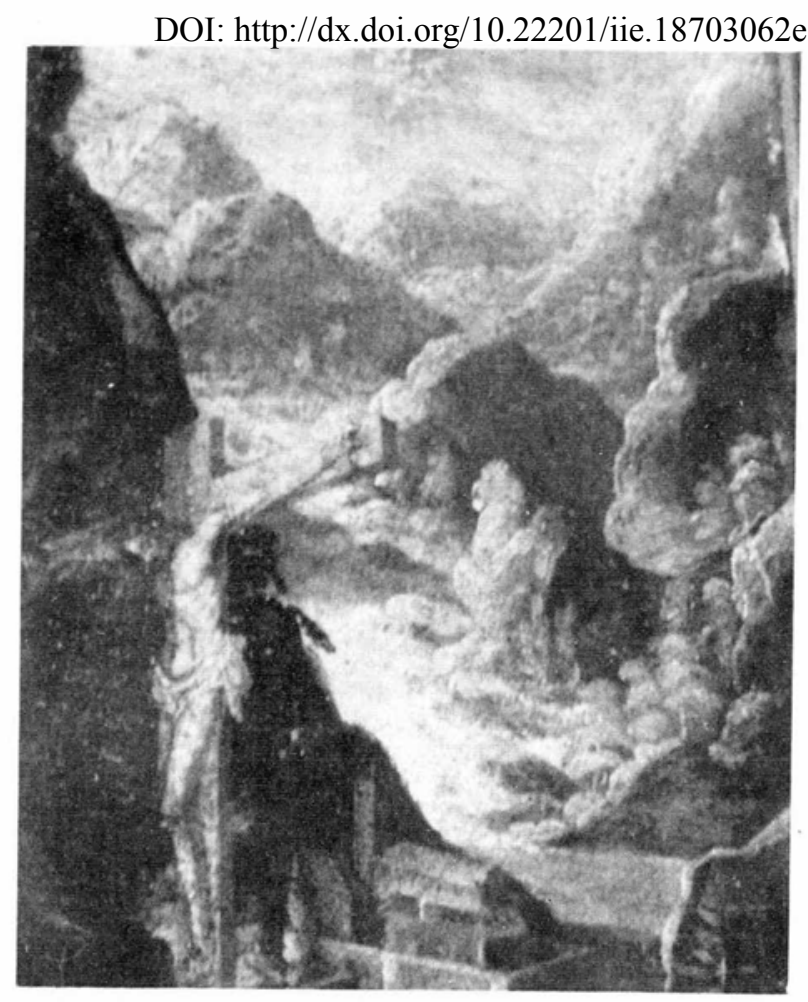

Figura 2. San Jerónimo. Detalle. Baltasar de Echave Ibía.



Figura 3. San Jerónimo. Detalle. Baltasar de Echave Ibía. 


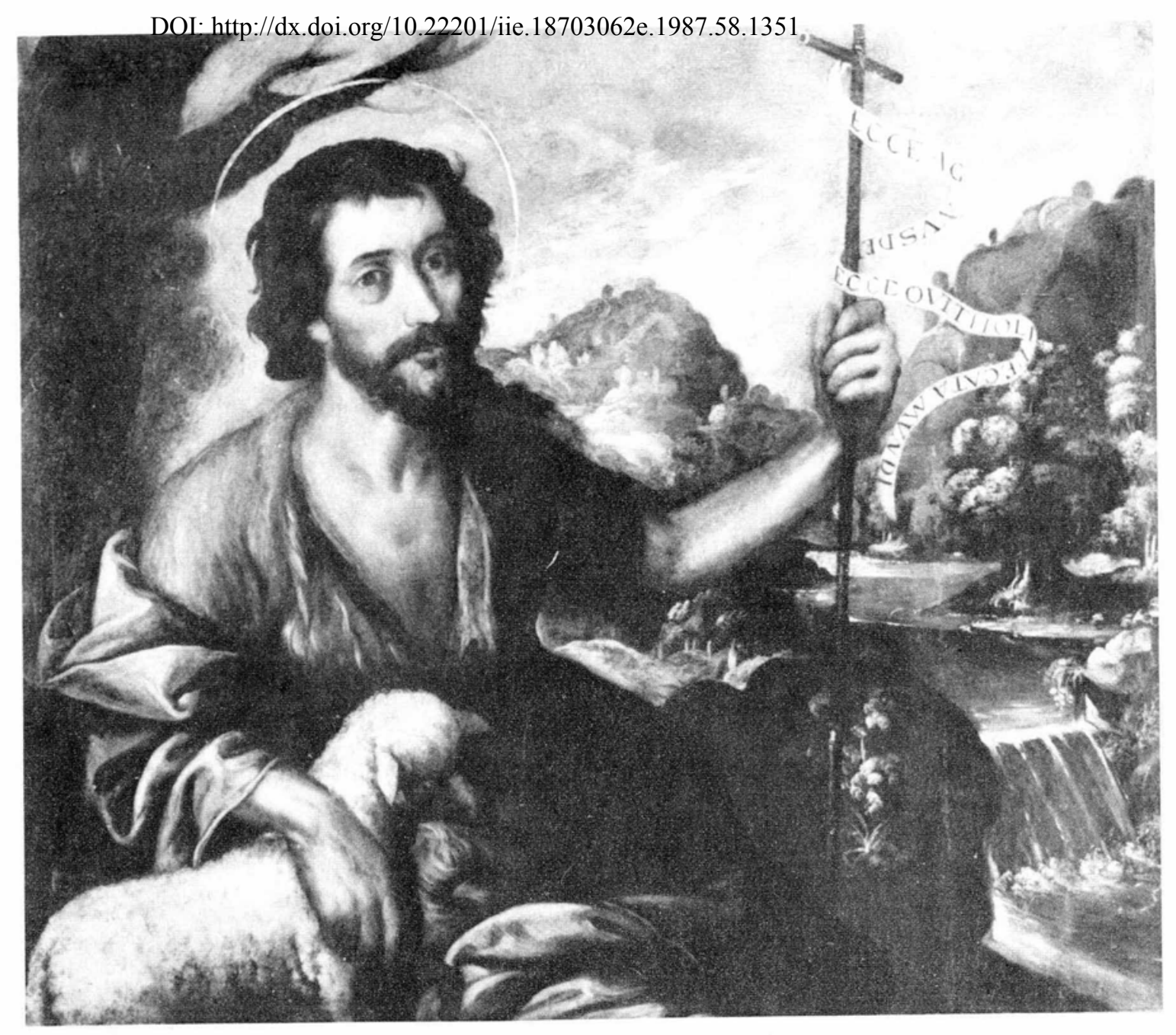

Figura 4. San Juan Bautista. Baltasar de Echave Ibía. 


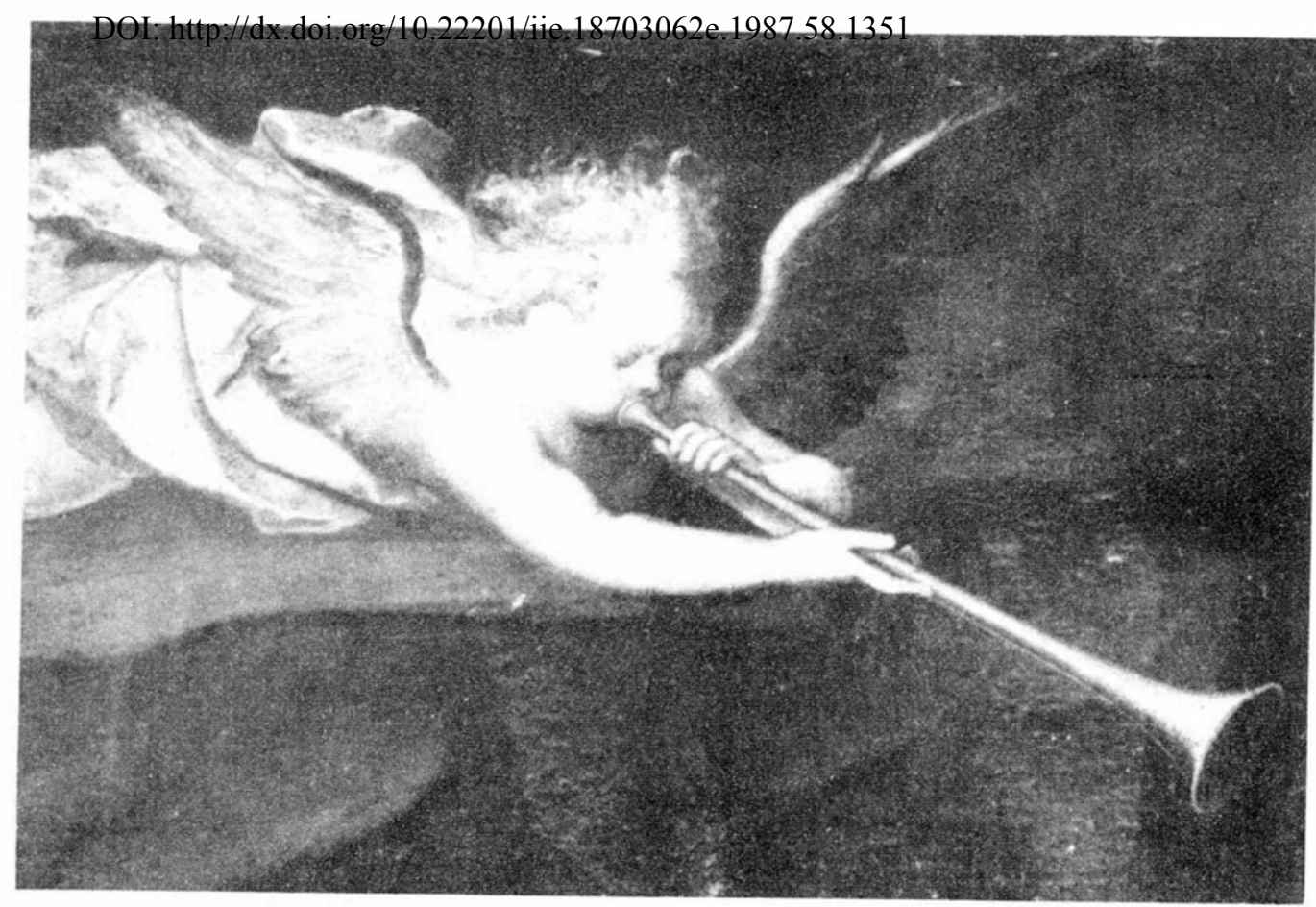

Figura 5. San Jerónimo. Detalle. Baltasar de Echave Ibía.

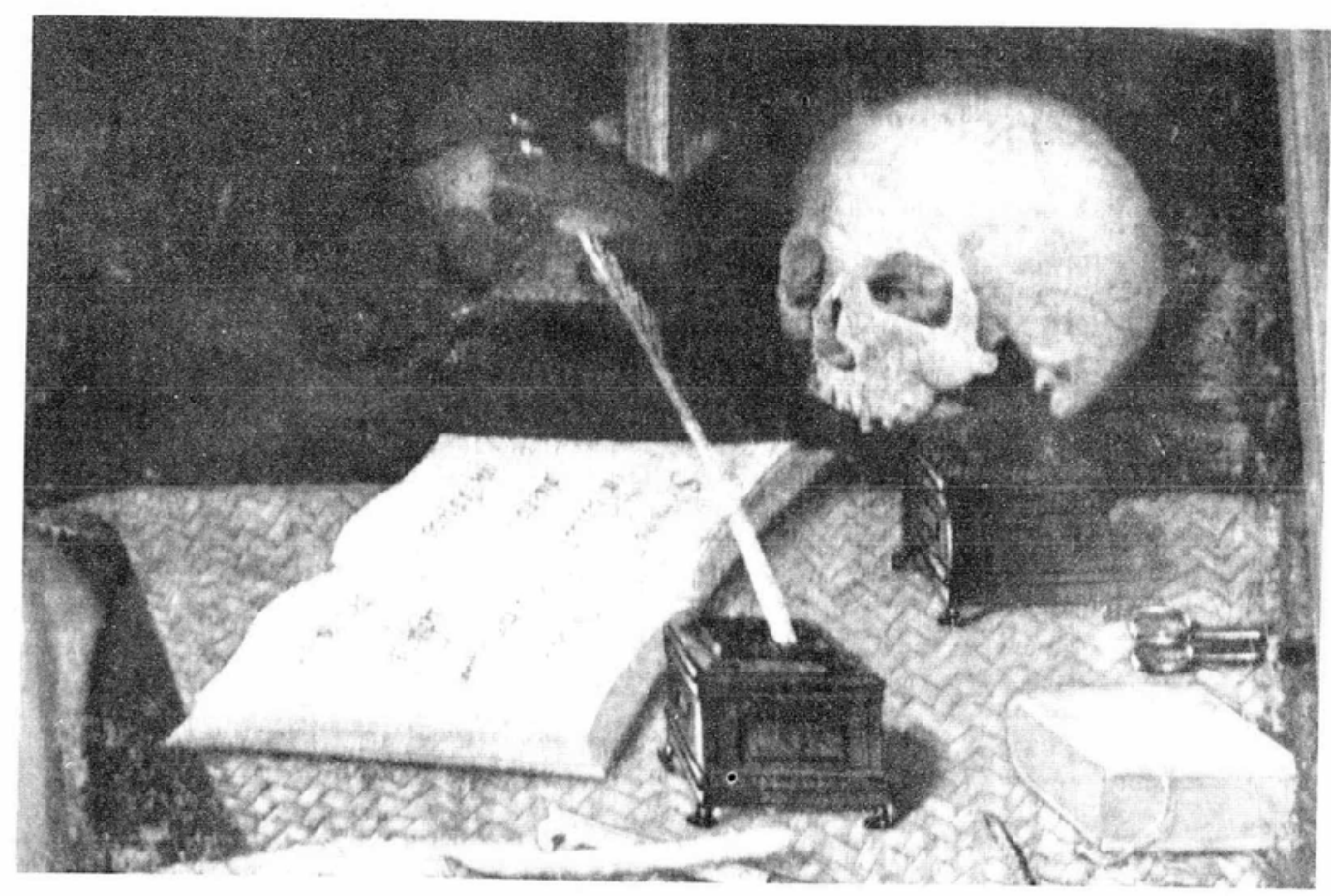

Figura 6. San Jerónimo. Detalle. Baltasar de Echave Ibía. 